\title{
The Conception of God \\ Address by Professor Royce
}

I cannot begin the discussion of this evening without heartily thanking first of all my friend the presiding officer, and then the members of the Philosophical Union, for the kindness which has given to me the wholly undeserved and the very manifold privileges which this occasion involves for the one whom your invitation authorises to lead the way in the discussion. It is a privilege to meet again many dear friends. It is a great privilege to be able to bring with me to my old home, as I do, the warm academic greetings of Harvard to my Alma Mater. It is an uncommon opportunity to encounter in a discussion of this sort my honoured colleagues who are tonight of your company. And there is another privilege involved for me in this occasion, which I must not omit to mention. I come here as a former student, to express as well as I can, by means of my poor performance of the present academic task, my thanks to the teachers who guided me in undergraduate days. It is the simplest duty of piety to them to say how I rejoice to be able to see, in this way, those of them who are still here, and with us tonight. Nor can I forbear, in this brief word of personal confession, to express with what especial earnestness of gratitude I come tonight into the presence of one of your number, and one of my former teachers, whose lectures and whose counsel were to

[Reprinted from CG, pp. 3-5o.] 
me, in my student days, especially a source of light, of guidance, and of inspiration. This teacher it was, I may say, who first set before me, in living presence, the ideal, still to me so remote, of the work of the thinker; and whenever since, in my halting way, I have tried to think about central problems, I have remembered that ideal of my undergraduate days,-that light and guidance and inspiration,-and the beloved teacher too, whose living presence in those days meant the embodiment of all these things. It is a peculiar delight, ladies and gentlemen,-a wholly undeserved boon,--to have this opportunity to come face to face, in your presence, with Professor Le Conte, and to talk with you, and with him, of questions that are indeed often called vexed questions, but that he first of all taught me to regard with the calmer piety and gentleness of the serious reason.

\section{God as the Omniscient Being, and Omniscience as Absolute Unity of Thought and Experience}

I have been asked to address the Philosophical Union upon some aspects of the problem of Theism. During the past year the Union has been devoting a very kind attention to a volume entitled The Religious Aspect of Philosopby, which I printed more than ten years ago. Were there time, I should be glad indeed if I were able to throw any direct light either upon that little book or upon your own discussions of its arguments. But, as a fact, my time in your presence is very short. The great problems of philosophy are pressing. I can do you more service on this occasion, if I devote myself to a somewhat independent confession of how the problems of philosophical Theism look to me to-day, than I could do if I took up your time with an effort to expound or defend a text which, as I frankly confess, I have not read with any care or connectedness since I finished the proof-sheets of the book in question. A man may properly print a philosophical essay for several reasons, taken in combination; namely, because he believes in it, and because he wants to get himself expressed, and, finally, because he wants to get freed from the accidents of just this train of thought. But, on the other hand, no philosophical student is ever persuaded of his opinions merely because he has formerly learned to believe them, or because he has once come to express them. The question for the philosophical student always is: How does the truth appear to me 
now, with the best reflection that I can at present give? Past expression is therefore no substitute for present effort in philosophy. The very essence of philosophy is an unconcern for every kind of tradition, just in so far as it has become to the individual student mere tradition. For while the contents of any tradition may be as sacred as you please, the traditional form, as such, is the very opposite of the philosophical form. A tradition may be true; but only a present and living insight can be philosophical. If this is the case with any tradition,--even a sacred tradition,--it is above all the case with the very poor and perhaps, if you will, very profane sort of tradition that an individual student of philosophy may find in the shape of a past piece of his own writing. It is the death of your philosophising, if you come to believe anything merely because you have once maintained it. And therefore I am not unwilling to confess that, if I had tonight to pass an examination upon the text of my book, I might very possibly get an extremely poor mark. Let us lay aside, then, for a moment, both text and tradition, and come face to face with our philosophical problem itself.

The Conception of God-this is our immediate topic. And I begin its consideration by saying that, to my mind, a really fruitful philosophical study of the conception of God is inseparable from an attempt to estimate what evidence there is for the existence of God. When one conceives of God, one does so because one is interested, not in the bare definition of a purely logical or mathematical notion, but in the attempt to make out what sort of real world this is in which you and I live. If it is worth while even to speak of God before the forum of the philosophical reason, it is so because one hopes to be able, in a measure, to translate into articulate terms the central mystery of our existence, and to get some notion about what is at the heart of the world. Therefore, when tonight I speak of the conception of God, I mean to do so in the closest relation to a train of thought concerning the philosophical proof that this conception corresponds to some living Reality. It is useless in this region to define unless one wishes to show that, corresponding to the definition, there is a reality. And, on the other hand, the proof that one can offer for God's presence at the heart of the world constitutes also the best exposition that one can suggest regarding what one means by the conception of God.

Yet, of course, some preliminary definition of what one has in mind when one uses the word "God" is of value, since our proof 
will then involve a development of the fuller meaning of just this preliminary definition. For this preliminary purpose, I propose to define, in advance, what we mean under the name "God," by means of using what tradition would call one of the Divine Attributes. I refer here to what has been called the attribute of Omniscience, or of the Divine Wisdom. By the word "God" I shall mean, then, in advance of any proof of God's existence, a being who is conceived as possessing to the full all logically possible knowledge, insight, wisdom. Our problem, then, becomes at once this: Does there demonstrably exist an Omniscient Being? or is the conception of an Omniscient Being, for all that we can say, a bare ideal of the human mind?

Why I choose this so-called attribute of Omniscience as constituting for the purposes of this argument the primary attribute of the Divine Being, students of philosophy-who remember, for instance, that the Aristotelian God, however his existence was proved, was defined by that thinker principally in terms of the attribute of Omniscience-will easily understand, and you, as members of this Union and readers of my former discussion, will perhaps especially comprehend. But, for the present, let this selection of the attribute of Omniscience, as giving us a preliminary definition of God, appear, if you will, as just the arbitrary choice of this address. What we here need to see from the outset, however, is that this conceived attribute of Omniscience, if it were once regarded as expressing the nature of a real being, would involve as a consequence the concurrent presence, in such a being, of attributes that we could at pleasure express under other names; such, for instance, as what is rationally meant by Omnipotence, by Self-Consciousness, by Self-Possession-yes, I should unhesitatingly add, by Goodness, by Perfection, by Peace. For, consider for an instant what must be meant by Omniscience if one undertakes for a moment to view an Omniscient Being as real.

An Omniscient Being would be one who simply found presented to him, not by virtue of fragmentary and gradually completed processes of inquiry, but by virtue of an all-embracing, direct, and transparent insight into his own truth,-who found thus presented to him, I say, the complete, the fulfilled answer to every genuinely rational question. Observe the terms used. I say, the answer to every question. The words are familiar. Consider their meaning. We mortals question. To question involves thinking of possible facts, 
or of what one may call possible experiences, that are not now present to us. Thinking of these conceived or possible experiences that we do not now possess, we question in so far as we ask either what it would be to possess them, or whether the world is such that, under given conditions, these experiences that we think of when we question could be presented to us. In other words, to question means to have ideas of what is not now present, and to ask whether these ideas do express, or could express, what some experience would verify. I question, on the country road: "Is it four miles to the railway station, or more, or less?" In this case I have ideas or thoughts about possible experiences not now present to me. I question in so far as I wonder whether these possible experiences, if I got them,-that is, if I walked or rode to yonder railway station and measured my way,-would fulfil or verify one or another of these my various thoughts or ideas about the distance. To be limited to mere questions, then,-and here is the essential point about questioning,-involves a certain divorce between your ideas and their objects, between facts conceived and facts directly experienced, between what you think about and what you regard as possibly to be presented to your direct experience. In this divorce of idea or thought and experience or fact, lies the essence of the state of mind of a being who merely questions.

On the other hand, to answer to the full, and with direct insight, any question, means to get your ideas, just in so far as they turn out to be true ideas, fulfilled, confirmed, verified by your experiences. When with full and complete insight you answer a question, then you get into the direct presence of facts, of experiences, which you behold as the confirmation or fulfilment of certain ideas, as the verification of certain thoughts. Take your mere ideas, as such, alone by themselves, and you have to question whether or no they are true accounts of facts. Answer your questions, wholly for yourself, without intermediation, and then you have got your ideas, your thoughts, somehow into the presence of experienced facts. There are thus two factors or elements in completed and genuine knowing, namely: fact, or something experienced, on the one hand; and mere idea, or pure thought about actual or possible experience, on the other hand. Divorce those two elements of knowledge, let the experienced fact, actual or possible, be remote from the idea or thought about it, and then the being who merely thinks, questions, and, so far, can only question. His state is such that he wonders: 
Is my idea true? But let the divorce be completely overcome, and then the being who fully knows answers questions, in so far as he simply sees his ideas fulfilled in the facts of his experience, and beholds his experiences as the fulfilment of his ideas.

Very well, then, an Omniscient Being is defined as one in whom these two factors of knowledge, so often divorced in us, are supposed to be fully and universally joined. Such a being, I have said, would behold answered, in the facts present to his experience, all rational, all logically possible questions. That is, for him, all genuinely significant, all truly thinkable ideas would be seen as directly fulfilled, and fulfilled in his own experience.

These two factors of his knowledge would, however, still remain distinguishable. He would think, or have ideas,-richer ideas than our present fragments of thought, I need not say; but he would think. And he would experience. That is, he would have, in perfect fulness, what we call feeling-a world of immediate data of consciousness, presented as facts. This his world of feeling, of presented fact, would be richer than our fragments of scattered sensation, as I also need not say; but he would experience. Only,-herein lies the essence of his conceived Omniscience,-in him and for him these facts would not be, as they often are in us, merely felt, but they would be seen as fulfilling his ideas; as answering what, were he not omniscient, would be his mere questions.

But now, in us, our ideas, our thoughts, our questions, not merely concern what experienced facts might come to us through our senses, but also concern the value, the worth, the relations, the whole significance, ethical or æsthetic, of our particular experiences themselves. We ask: Shall I win success? And the question implies the idea of an experience of success which we now have not. We ask: What ought I to do? And the question involves the idea of an experience of doing, which we conceive as fulfilling the idea of right. Misfortune comes to us, and we ask: What means this horror of my fragmentary experience? - why did this happen to me? The question involves the idea of an experience that, if present, would answer the question. Now such an experience, if it were present to us, would be an experience of a certain passing through pain to peace, of a certain winning of triumph through partial defeat, of a certain far more exceeding weight of glory that would give even this fragmentary horror its place in an experience 
of triumph and of self-possession. In brief, every time we are weak, downcast, horror-stricken, alone with our sin, the victims of evil fortune or of our own baseness, we stand, as we all know, not only in presence of agonising fragmentary experiences, but in presence of besetting problems, which in fact constitute the very heart of our calamity. We are beset by questions to which we now get no answers. Those questions could only be answered, those bitter problems that pierce our hearts with the keen edge of doubt and of wonder,-when friends part, when lovers weep, when the lightning of fortune blasts our hopes, when remorse and failure make desolate the lonely hours of our private despair,-such questions, such problems, I say, could only be answered if the flickering ideas then present in the midst of our darkness shone steadily in the presence of some world of superhuman experience, of which ours would then seem to be only the remote hint. Such superhuman experience might in its wholeness at once contain the answer to our questions, and the triumph over-yes, and through-our fragmentary experience. But, as we are, we can only question.

Well, then,-if the divorce of idea and experience characterises every form of our human consciousness of finitude, of weakness, of evil, of sin, of despair,-you see that Omniscience, involving, by definition, the complete and final fulfilment of idea in experience, the unity of thought and fact, the illumination of feeling by comprehension, would be an attribute implying, for the being who possessed it, much more than a universally clear but absolutely passionless insight. An Omniscient Being could answer your bitter Why? when you mourn, with an experience that would not simply ignore your passion. For your passion, too, is a fact. It is experiienced. The experience of the Omniscient Being would therefore include it. Only his insight, unlike yours, would comprehend it, and so would answer whatever is rational about your present question.

This is what I mean by saying that the definition of God by means of the attribute of Omniscience would involve far more than the phrase "mere omniscience" at first easily suggests. As a fact, in order to have the attribute of Omniscience, a being would necessarily be conceived as essentially world-possessing,-as the source and principle of the universe of truth,-not merely as an external observer of a world of foreign truth. As such, he would 
be conceived as omnipotent, and also in possession of just such experience as ideally ought to be; in other words, as good and perfect.

So much, then, for the mere preliminary definition. To this definition I should here add a word or two of more technical analysis. We mortals have an incomplete experience. This means that the ideas awakened in us by our experience far transcend what we are now able to verify. We think, then, of actual or of possible experience that is not now ours. But an Omniscient Being would have no genuine or logically permissible ideas of any experience actually beyond his own or remote from his own. We express this by saying, technically, that an Omniscient Being would possess an Absolute Experience; that is, a wholly complete or selfcontained experience, not a mere part of some larger whole. Again, the Omniscient Being would be, as we have said, a thinker. But we, as thinkers, are limited, both in so far as there is possible thought not yet attained by us, and in so far as we often do not know what ones amongst our thoughts or ideas have a genuine meaning, or correspond to what an absolute experience would fulfil. But the Omniscient Being would not be thus limited as to his thinking. Accordingly, he would possess what we may call an Absolute Thought; that is, a self-contained thought, sufficient unto itself, and needing no further comment, supplement, or correction. As the union of such an Absolute Thought and Absolute Experience, our Omniscient Being is technically to be named simply the Absolute; that is, the being sufficient unto himself. Moreover, I should also say that the experience and thought of this being might be called completely or fully organised. For us, namely, facts come in a disjointed way, out of connexion; and our thoughts, equally, seek a connexion which they do not now possess. An Omniscient Being would have to have present to himself all the conceivable relations amongst facts, so that in his world nothing would be fragmentary, disunited, confused, unrelated. To the question: What is the connexion of this and this in the world? the Omniscient Being would simply always find present the fulfilled answer. His experience, then, would form one whole. There would be endless variety in this whole, but the whole, as such, would fulfil an all-embracing unity, a single system of ideas. This is what I mean by calling his Experience, as we here conceive it, an abso- 
lutely organised experience, his Thought an absolutely organised thought.

And now our question returns. We have defined the Omniscient Being. The question is: Does such a being exist? We turn from the ideal to the hard fact that we mortals find ourselves very ignorant beings. What can such as we are hope to know of the Absolute?

\section{First Definition of Human Ignorance, Apparently Excluding Knowledge of Reality}

Yes, the vast extent of our human ignorance, the limitations of our finite knowledge,--these great facts, so familiar to the present generation, confront us at the outset of every inquiry into our knowledge about God, or about any absolute issue. So little am I disposed to neglect these great facts of our limitation, that, as perhaps you will remember from the book that you studied, philosophy seems to me, primarily, to be as much the theory of human ignorance as it is the theory of human knowledge. In fact, it is a small thing to say that man is ignorant. It is a great thing to undertake to comprehend the essence, the form, the implications, the meaning, of human ignorance. Let us make a beginning in this task as we approach the problem of Theism. For my thesis to-night will be that the very nature of human ignorance is such that you cannot conceive or define it apart from the assertion that there is, in truth, at the heart of the world, an Absolute and Universal Intelligence, for which thought and experience, so divided in us, are in complete and harmonious unity.

"Man is ignorant," says one,-“ignorant of the true nature of reality. He knows that in the world there is something real, but he does not know what this reality is. The Ultimate Reality can therefore be defined, from our human point of view, as something unknowable." Here is a thesis nowadays often and plausibly maintained. Let me remind you of one or two of the customary arguments for this thesis-a thesis which, for us on this occasion, shall constitute a sort of first attempt at a definition of the nature of our human ignorance.

All that we know or can know, so the defenders of this thesis assert, must first be indicated to us through our experience. With- 
out experience, without the element of brute fact thrust upon us in immediate feeling, there is no knowledge. Now, so far, as I must at once assure you, I absolutely accept this view. This is true, and there is no escape from the fact. Apart from-that is, in divorce from-experience there is no knowledge. And we can come to know only what experience has first indicated to us. I willingly insist that philosophy and life must join hands in asserting this truth. The whole problem of our knowledge, whether of Nature, of man, or of God, may be condensed into the one question: What does our experience indicate? But, to be sure, experience, as it first comes to us mortals, is not yet insight. Feeling is not yet truth. The problem: What does our experience indicate? implies in its very wording that the indication is not the result. And between the indication and the truth that experience indicates there actually lies the whole travail of the most abstruse science.

But the partisans of our present thesis continue their parable thus: This being true,-experience being the life-blood of our human knowledge,-it is a fact that our human experience is determined by our peculiar organisation. In particular, the specific energies of our sensory nerves determine our whole experience of the physical world. The visual centres get affected from without in such wise only that sensations of light accompany their excitement. The auditory centres respond to sensory disturbance in such wise only that we hear sounds. The physical fact beyond us never gets directly represented in our mental state; for between the physical fact and our experience of its presence lie the complex conditions that give our sensations their whole specific character. And what is true of our sensations is true of the rest of our experience. As it comes to us, this experience is our specific and mental way of responding to the stimulations which reality gives us. This whole specific way therefore represents, not the true nature of outer reality, so much as the current states of our own organisations. Were the outer reality, as it exists not for our senses but in itself, to be utterly altered, still our experience, so long as one supposed our organisation itself somehow to survive in a relatively unchanged form, might retain very many of its present characters -so many, in fact, that we need not necessarily suspect the metaphysical vastness of the change. On the other hand, if even a very slight cause, such as the inhaling of a little nitrous oxide or chloroform, chances to alter some essential process in the organisation 
upon which our specific sort of experience depends, then at once our whole immediate experience undergoes a vast change, and it is as if our world came to an end, and a new world began. Yet the metaphysically real alteration of the universe in such a case may be almost inappreciable.

Thus, then, our experience changes with the current states of our own organisations, rather than reveals the reality beyond; and this reality beyond, as it is in itself, remains unknowable. So far, the well-known and popular argument for agnosticism as to every form of absolute truth.

\section{Higher Definition of Human Ignorance, Vindicating a Knowledge of Reality}

This first definition of the nature of our ignorance is a very familiar one in the present day. It is a definition that contains, but also, as I must add, conceals, a great deal of truth. I do not know how many times or in how many forms you may meet with it in current literature. You often seem to be meeting it everywhere. I regard it, however, as a statement of a truth in a form so confused as to be almost useless, without revision.

And first, let me ask, when one thus laments our ignorance of the supposed Absolute Reality, what it is that he desires as his unattainable goal, when he thus laments. You cannot rationally say "I lack," without being properly called upon to define, in some intelligible terms, what you suppose yourself to be lacking. And I know not how the present question can be answered, unless thus: That which man now lacks, in so far as he is ignorant of the Absolute Reality, is logically definable as a possible, but to us unattainable, sort of experience; namely, precisely an experience of what reality is. And I lay stress upon this view, in order simply to point out that our ignorance of reality cannot mean an ignorance of some object that we can conceive as existing apart from any possible experience or knowledge of what it is. What you and I lack, when we lament our human ignorance, is simply a certain desirable and logically possible state of mind, or type of experience; to wit, a state of mind in which we should wisely be able to say that we had fulfilled in experience what we now have merely in idea, namely, the knowledge, the immediate and felt presence, of what we now call the Absolute Reality. 
Let us remember, then, this first simple insight: That our ignorance of the Absolute Reality can mean only that there is some sort of possible experience, some state of mind, that you and I want, but that we do not now possess. And next let us proceed to ask why it is that the foregoing popular argument for our human ignorance has seemed to us so convincing,-as it usually does seem. Why is it that when men say: "You are confined to your sensations, and your sensations never reveal to you the external physical realities as they are in themselves," this argument seems so crushing, this exposure of our human fallibility so impressive?

To this question I answer, that, as a fact, the argument just stated from the physiology of the senses convinces us of our human fallibility and ignorance so persuasively, only because, in the concrete application of this argument, we actually first assume that we have a real knowledge, not, to be sure, of ultimate truth, but of a truth known to us through a higher experience than that of our senses; namely, the experience of that very science of the physiology of the senses which is relied upon to prove our total ignorance. When compared with this assumed higher form of indirect experience, or scientific knowledge, the direct experience of the senses does indeed seem ignorant and fallible enough. For the foregoing argument depends upon the supposition that we do know very well what we mean by the physical states of our organisms, and by the physical events outside of us. And the thesis involved is, in this aspect, simply the doctrine that any given group of sensations, e.g. those of colour, of temperature, or of odour, are inadequate indications of the otherwise known or knowable physical properties of the bodies that affect us when we see or feel or smell in their presence. On this side, then, I insist, the doctrine that our sensory experience is dependent upon the physical states of our organism is a doctrine expressive, not of our ignorance of any Absolute Reality (or Ding an sich), but of our knowledge of a phenomenal world. We happen to know, or at all events to believe that we know, concerning what our experience reveals and our science analyses, viz., concerning the so-called physical world, so much, that we can actually prove the inadequacy of our current sensations to reveal directly, or to present to us, physical truths that our science otherwise, and more indirectly, well makes out. The relatively indirect experience of science can and does correct the existent and unconquerable momentary ignorance of our 
senses. Indirect insight proves to be better, in some ways, than immediate feeling. To use Professor James's more familiar terminology, we declare that we know about the physical world more than we can ever grasp by direct acquaintance with our sensations. And so, now, it is because we are supposed to know these things about the so-called reality, that we are aware of the limitations of our passing experiences. Thus viewed, the present statement of our limitations appears to be merely a correction of our narrower experience by the organised experience of our race and of our science. It tells us that we are ignorant, in one region of our experience, of what a wider experience, indirectly acquired, reveals to us.

The physiology of the senses, then, rightly viewed, does not assert that all our human experience is vainly subjective, including the very type of experience upon which the sciences themselves are founded. What science says is simply that there is a sort of indirect and organised experience which reveals more of phenomenal truth than can ever be revealed to our direct sensory states as these pass by. But our popular doctrine of the Unknowable Reality uses this so-called "verdict of science" only by confounding it with a totally different assertion. The "verdict of science" is that organised experience indicates much phenomenal truth that the senses can never directly catch. The doctrine of the Unknowable Reality asserts that no human experience can attain any genuine truth, and then appeals to that aforesaid "verdict" to prove this result. But the sciences judge the ignorance of sense by comparing it with a knowledge conceived to be actually attained; namely, the knowledge of certain indirectly known physical phenomena as they really are, not to be sure as absolute realities, but as the objects of our organised physical experience. You surely cannot use the proposition that organised experience is wiser than passing experience, to prove that no experience can give us any true wisdom.

\section{Ignorance Defined as Unorganised Experience, and as Implying an Experience Absolutely Organised}

Yet I said, a moment ago, that this popular conception of the nature of our human ignorance contains-or, rather, concealsmuch truth. And this notion of the relative failure of every sort of merely immediate experience to reveal a truth at which it kindly 
hints, is a very instructive notion. Only, we plainly need to try a second time to define the nature of human ignorance, in terms of this very contrast between a lower and a higher sort of experience. Let us begin anew our analysis of this same significant problem of the nature and limits of knowledge.

The fortune of our empirical science has been, that as we men have wrought together upon the data of our senses, we have gradually woven a vast web of what we call relatively connected, united, or organised knowledge. It is of this world, in its contrast with the world of our sensations, that I have just been speaking. Now, as we have just seen, this organised knowledge has a very curious relation to our more direct experience. In the first place, wherever this organised knowledge seems best developed, we find it undertaking to deal with a world of truth, of so-called reality, or at least of apparent truth and reality, which is very remote from the actual sensory data that any man of us has ever beheld. Our organised science, as many have pointed out ever since Plato's first naïve but permanently important observations upon this topic, deals very largely with conceived-with ideal-realities, that transcend actual human observation. Atoms, ether-waves, geological periods, processes of evolution,--these are to-day some of the most important constituents of our conceived phenomenal universe. Spatial relations, far more exactly describable than they are directly verifiable, mathematical formulæ that express again the exactly describable aspects of vast physical processes of change,-such are the topics with which our exacter science is most immediately concerned. In whose sensory experience are such objects and relationships at all directly pictured? The ideal world of Plato, the product of a more elementary sort of infant science, was made up of simpler contents than these; but still, when thus viewed, our science does indeed seem as if absorbed in the contemplation of a world of pure,-yes, I repeat, of Platonic ideas. For such realities get directly presented to no man's senses.

But of course, on the other hand, we no sooner try to define the work of our science in these terms than we are afresh reminded that this realm of pure Platonic ideas would be a mere world of fantastic shadows if we had not good reason to say that these ideas, these laws, these principles, these ideal objects of science, remote as they seem from our momentary sensory experiences, still have a real and, in the end, a verifiable relation to actual experience. 
One uses the scientific conceptions because, as one says, one can verify their reality. And to verify must mean to confirm in sensory terms. Only, to be sure, such verification always has to be for us men an extremely indirect one. The conceived realities of constructive science,-atoms, molecules, ether-waves, geological periods, processes of change whose type is embodied in mathematical formulx,-these are never directly presented to any moment of our verifying sensory experience. But nevertheless we say that science does verify these conceptions; for science computes that if they are true, then, under given conditions, particular sensory experiences, of a predictable character, will occur in somebody's individual experience. Such predictions trained observers can and do successfully undertake to verify. The verification is itself, indeed, no direct acquaintance with the so-called realities that the aforesaid Platonic ideas define. But it appears to involve an indirect knowledge about such realities.

Yet our direct experience, as it actually comes, remains at best but a heap of fragments. And when one says that our science reduces our experience to order, one is still talking in relatively ideal terms. For our science does not in the least succeed in effectively reducing this chaos of our finite sensory life to any directly presented orderly wholeness. For think, I beg you, of what our concrete human experience is, as it actually comes, even at its best. Here we are all only too much alike. The sensory experience of a scientific man is, on the whole, nearly as full of immediately experienced disorder and fragmentariness as is that of his fellow the layman. For the scientific student too, the dust of the moment flies, and this dust often fills his eyes, and blinds him with its whirl of chance almost as much as it torments his neighbour who knows no Platonic ideas. I insist: Science throughout makes use of the contrast between this flying experience which we have, and which we call an experience of unreality, and the ideal experience, the higher sort of organised experience which we have not, and which we call an experience of reality. Upon this contrast the whole confession of our human ignorance depends. Let us still dwell a little on this contrast. Remember how full of mere chance the experience of nearly every moment seems to be; and that, too, even in a laboratory; much more, in a day's walk or in a lecture-room. The wind that sighs; the cart or the carriage that rumbles by; yonder dress or paper that rustles; the chair or boot that squeaks; 
the twinge that one suddenly feels; the confusions of our associative mental process, "fancy unto fancy linking"; the accidents that filled to-day's newspapers,-of such stuff, I beg you to notice, our immediate experience is naturally made up. The isolating devices of the laboratory, the nightly silence of the lonely observatory, the narrowness of the microscopic field, and, best of all, the control of a fixed and well-trained attention, often greatly diminish, but simply cannot annul, the disorder of this outer and inner chaos. But, on the other hand, all such efforts to secure order rest on the presupposition that this disorder means fragmentarinessrandom selection from a world of data that our science aims to view indirectly as a world of orderly experience. But even such relative reduction of the chaos as we get never lasts long and continuously in the life of any one person. Your moments of unfragmentary and more scientific experience fill of themselves only fragments of your life. A wandering attention, the interruption of intruding sensations,--such fragments may at any time be ready, by their intrusion, to destroy the orderliness of even the bestequipped scientific experience. The student of science, like other men, knows in fragments, and prophesies in fragments. But-and here we come again in sight of our goal-the world of truth that he wants to know is a world where that which is in part is to be taken away. He calls that the world of an organised experience. But he sees that world as through a glass,-darkly. He has to ignore his and our ignorance whenever he speaks of such a world as if it were the actual object of any human experience whatever. As a fact, direct human experience, apart from the elaborately devised indirect contrivances of conceptual thought, knows nothing of it.

But let us sum up the situation now before us. It is the very situation that our first statement of human ignorance as dependent on our organisation tried to define. We now define afresh. All our actual sensory experience comes in passing moments, and is fragmentary. Our science, wherever it has taken any form, contrasts with this immediate fragmentariness of our experience the assertion of a world of phenomenal truth, which is first of all characterised by the fact that for us it is a conceptual world, and not a world directly experienced by any one of us. Yet this ideal world is not an arbitrary world. It is linked to our actual experience by the fact that its conceptions are accounts, as exact as may be, of systems of possible experience, whose contents would be presented, 
in a certain form and order, to beings whom we conceive as including our fragmentary moments in some sort of definite unity of experience. That these scientific accounts of this world of organised experience are true, at least in a measure, we are said to verify, in so far as, first, we predict that, if they are true, certain other fragmentary phenomena will get presented to us under certain definable conditions, and in so far as, secondly, we successfully proceed to fulfil such predictions. Thus all of our knowledge of natural truth depends upon contrasting our actually fragmentary and stubbornly chaotic individual and momentary experience with a conceived world of organised experience, inclusive of all our fragments, but reduced in its wholeness to some sort of all-embracing unity. The contents and objects of this unified experience, we discover first by means of hypotheses as to what these contents and objects are, and then by means of verifications which depend upon a successful retranslation of our hypotheses as to organised experience into terms which our fragmentary experience can, under certain conditions, once more fulfil.

If, however, this is the work of all our science, then the conception of our human ignorance easily gets a provisional restatement. You are ignorant, in so far as you desire a knowledge that you cannot now get. Now, the knowledge you desire is, from our present point of view, no longer any knowledge of a reality foreign to all possible experience; but it is an adequate knowledge of the contents and the objects of a certain conceived or ideal sort of experience, called by you organised experience. And an organised experience would be one that found a system of ideas fulfilled in and by its facts. This sort of knowledge, you, as human being, can only define indirectly, tentatively, slowly, fallibly. And you get at it thus imperfectly,-why? Because your immediate experience, as it comes, is always fleeting, fragmentary. This is the sort of direct knower that you are,-a being who can of himself verify only fragments. But you can conceive infinitely more than you can directly verify. In thought you therefore construct conceptions which start, indeed, in your fragmentary experience, but which transcend it infinitely, and which so do inevitably run into danger of becoming mere shadows-pure Platonic ideas. But you don't mean your conceptions to remain thus shadowy. By the devices of hypothesis, prediction, and verification, you seek to link anew the concept and the presentation, the ideal order and the 
stubborn chaos, the conceived truth and the immediate datum, the contents of the organised experience and the fragments of your momentary flight of sensations. In so far as you succeed in this effort, you say that you have science. In so far as you are always, in presented experience, limited to your chaos, you admit that your sensations are of subjective moment and often delude you. But in so far as your conceptions of the contents of the ideal organised experience get verified, you say that you acquire the aforesaid indirect knowledge of the contents of the ideal and organised experience. We men know all things through contrasts. It is the contrast of your supposed indirect knowledge of the contents of the ideal organised experience with your direct and actual, but fragmentary, passing experience, that enables you to confess your ignorance. Were you merely ignorant, you could not know the fact. Because you are indirectly assured of the truth of an insight that you cannot directly share, you accuse your direct experience of illusory fragmentariness. But in so doing you contrast the contents of your individual experience, not with any mere reality apart from any possible experience, but with the conceived object of an ideal organised experience-an object conceived to be present to that experience as directly as your sensory experiences are present to you.

\section{Reality and Experience as Correlative Conceptions}

In the light of such considerations, our notion of the infinitely remote goal of human knowledge gets a transformation of a sort very familiar to all students of philosophical Idealism. And this transformation relates to two aspects of our conception of knowledge, viz.: first, to our notion of what reality is, and secondly to our notion of what we mean by that Organised Experience. In the first place, the reality that we seek to know has always to be defined as that which either is or would be present to a sort of experience which we ideally define as an organised-that is, a united and transparently reasonable-experience. We have, in point of fact, no conception of reality capable of definition except this one. In case of an ordinary illusion of the senses we often say: This object seems thus or so; but in reality it is thus. Now, here the seeming is opposed to the reality only in so far as the chance experience of one point of view gets contrasted with what would 
be, or might be, experienced from some larger, more rationally permanent, or more inclusive and uniting point of view. Just so, the temperature of the room seems to a fevered patient to vary thus or thus; but the real temperature remains all the while nearly constant. Here the seeming is the content of the patient's momentary experience. The real temperature is a fact that either is, or conceivably might be, present to a larger, a more organised and scientific and united experience, such as his physician may come nearer than himself to possessing. The sun seems to rise and set; but in reality the earth turns on its axis. Here the apparent movement of the sun is somewhat indirectly presented to a narrow sort of human experience. A wider experience, say an experience defined from an extra-terrestrial point of view, would have presented to it the earth's rotation as immediately as we now can get the sunrise presented to us. To conceive any human belief as falsesay, the belief of a lunatic, a fanatic, a philosopher, or a theologian -is to conceive this opinion as either possibly or actually corrected from some higher point of view, to which a larger whole of experience is considered as present.

Passing to the limit in this direction, we can accordingly say that by the absolute reality we can only mean either that which is present to an absolutely organised experience inclusive of all possible experience, or that which would be presented as the content of such an experience if there were one. If there concretely is such an absolute experience, then there concretely is such a reality present to it. If the absolute experience, however, remains to the end barely possible, then the concept of reality must be tainted by the same bare possibility. But the two concepts are strictly correlated. To conceive, for instance, absolute reality as containing no God, means simply that an absolutely all-embracing experience, if there were one, would find nothing Divine in the world. To assert that all human experience is illusory, is to say that an absolutely inclusive experience, if there were one, would have present, as part of its content, something involving the utter failure of our experience to attain that absolute content as such. To conceive that absolute reality consists of material atoms and ether, is to say that a complete experience of the universe would find presented to it nothing but experiences analogous to those that we have when we talk of matter in motion. In short, one must be serious with this concept of experience. Reality, as opposed to illusion, means 
simply an actual or possible content of experience, not in so far as this experience is supposed to be transient and fleeting, but in so far as it is conceived to be somehow inclusive and organised, the fulfilment of a system of ideas, the answer to a scheme of rational questions.

It remains, however, to analyse the other member of our related pair of terms, viz.: the conception of this organised sort of experience itself. In what sense can there be any meaning or truth about this conception?

\section{Analysis of the Conception Absolute Experience: "Meaning of its Reality}

The conception of organised experience, in the limited and relative form in which the special sciences possess it, is unquestionably through and through a conception that for us men, as we are, has a social origin. No man, if isolated, could develope the sort of thoughtfulness that would lead him to appeal from experience as it comes to him to experience as it ideally ought to come, or would come, to him in case he could widely organise a whole world of experience in clear relation to a single system of conceptions. Man begins his intelligent life by imitatively appealing to his fellow's experience. The life-blood of science is distrust of individual belief as such. A common definition of a relatively organised experience is, the consensus of the competent observers. Deeper than our belief in any physical truth is our common-sense assurance that the experience of our fellows is as genuine as our own, is in actual relation to our own, has present to it objects identical with those that we ourselves experience, and consequently supplements our own. Apart from our social consciousness, I myself should hold that we men, growing up as we do, can come to have no clear conception of truth, nor any definite power clearly to think at all. Every man verifies for himself. But what he verifies, - the truth that he believes himself to be making out when he verifies,-this he conceives as a truth either actually or possibly verifiable by his fellow or by some still more organised sort of experience. And it becomes for him a concrete truth, and not a merely conceived possibility, precisely so far as he believes that his fellow or some other concrete mind does verify it.

My fellow's experience, however, thus supplements my own in 
two senses; namely, as actual and as possible experience. First, in so far as I am a social being, I take my fellow's experience to be as live and real an experience as is mine. In appealing to the consensus of other men's experiences, I am so far appealing to what I regard as a real experience other than my own momentary experience, and not as a merely possible experience. But in this sense, to be sure, human experience is not precisely an organised whole. Other men experience in passing moments, just as I do. Their consensus, in so far as it is reached, is no one whole of organised experience at all. But, on the other hand, the fact of the consensus of the various experiences of men, so far as such consensus appears to have been reached, suggests to our conception an ideal-the ideal of an experience which should be not only manifold but united, not only possessed of chance agreements but reduced to an all-embracing connectedness. As a fact, this ideal is the one constantly used by anyone who talks of the "verdict of science." This significant, whole, and connected experience remains, to us mortals, a conceived ideal,-always sought, never present. The ultimate question is: Is this conception a mere ideal? -or does it stand for a genuine sort of concrete experience? The social origin of the conception, as we mortals have come to get it, suggests in an ambiguous way both alternatives. The experience to which, as a social being, I first appeal when I learn to talk of truth, is the live actual experience of other men, which I, as an imitative being, primarily long to share, and which I therefore naturally regard as in many respects the norm for my experience. In society, in so far as I am plastic, my primary feeling is that I ought, on the whole, to experience what the other men experience. But in the course of more thoughtful mental growth, we have come to appeal from what the various men do experience to what they all ought to experience, or would experience if their experiences were in unity; that is, if all their moments were linked expressions of one universal meaning which was present to one Universal Subject, of whose insight their own experiences were but fragments. Such an ideally united experience, if it could but absolutely define its own contents, would know reality. And by reality we mean merely the contents that would be present to such an ideal unity of experience. But now, on this side, the conception of the ideally organised experience does indeed at first look like a mere ideal of a barely possible unity. The problem still is: Is this unity more than a bare 
possibility? Has it any such concrete genuineness as the life of our fellows is believed to possess?

Observe, however, that our question: Is there any such real unity of organised experience? is precisely equivalent to the question: Is there, not as a mere possibility, but as a genuine truth, any reality? The question: Is there an absolutely organised experience? is equivalent to the question: Is there an absolute reality? You cannot first say: There is a reality now unknown to us mortals, and then go on to ask whether there is an experience to which such reality is presented. The terms "reality" and "organised experience" are correlative terms. The one can only be defined as the object, the content, of the other. Drop either, and the other vanishes. Make one a bare ideal, and the other becomes equally such. If the organised experience is a bare and ideal possibility, then the reality is a mere seeming. If what I ought to experience, and should experience were I not ignorant, remains only a possibility, then there is no absolute reality, but only possibility, in the universe, apart from your passing feelings and mine. Our actual issue, then, is: Does a real world ultimately exist at all? If it does, then it exists as the object of some sort of concretely actual organised experience, of the general type which our science indirectly and ideally defines, only of this type carried to its absolute limit of completeness.

The answer to the ultimate question now before us-the question: Is there an absolutely organised experience?-is suggested by two very significant considerations. Of these two considerations, the first runs as follows:

The alternative to saying that there is such a real unity of experience is the assertion that such a unity is a bare and ideal possibility. But, now, there can be no such thing as a merely possible truth, definable apart from some actual experience. To say: So and so is possible, is to say: There is, somewhere in experience, an actuality some aspect of which can be defined in terms of this possibility. A possibility is a truth expressed in terms of a proposition beginning with if, or a hypothetical proposition,-an is expressed in terms of an if. But every hypothetical proposition involves a categorical proposition. Every if implies an is. For you cannot define a truth as concretely true unless you define it as really present to some experience. Thus, for instance, I can easily define my actual experience by expressing some aspect of it in the form 
of a supposition, even if the supposition be one contrary to fact, but I cannot believe in the truth of such a supposition without believing in some concrete and experienced fact. The suitor asks for the daughter. The father replies: "I will give thee my daughter if thou canst touch heaven." Here the father expresses his actually experienced intention in the form of a hypothetical proposition each member of which he believes to be false. The suitor cannot touch heaven, and is not to get the gift of the daughter. Yet the hypothetical proposition is to be true. Why? Because it expresses in terms of an if what the father experiences in terms of an is, namely, the obdurate inner will of the forbidding parent himself. Just so with any if proposition. Its members, antecedent and consequent, may be false. But it is true only in case there corresponds to its fashion of assertion some real experience.

And now, to apply this thought to our central problem: You and I, whenever we talk of reality as opposed to mere seeming, assert of necessity, as has just been shown, that if there were an organised unity of experience, this organised experience would bave present to it as part of its content the fact whose reality we assert. This proposition cannot, as a merely hypothetic proposition, have any real truth unless to its asserted possibility there corresponds some actual experience, present somewhere in the world, not of barely possible, but of concretely actual experience. And this is the first of our two considerations. In fine, if there is an actual experience to which an absolute reality corresponds, then you can indeed translate this actuality into the terms of bare possibility. But unless there is such an actual experience, the bare possibility expresses no truth.

The second consideration appears when we ask our finite experience whereabouts, in its limited circle, is in any wise even suggested the actually experienced fact of which that hypothetical proposition relating to the ideal or absolute experience is the expression. What in finite experience suggests the truth that if there were an absolute experience it would find a certain unity of facts?

\section{Proof of the Reality of an Absolute Experience}

To the foregoing question, my answer is this: Any finite experience either regards itself as suggesting some sort of truth, or does not so regard itself. If it does not regard itself as suggesting truth, 
it concerns us not here. Enough, one who thinks, who aims at truth, who means to know anything, is regarding his experience as suggesting truth. Now, to regard our experience as suggesting truth is, as we have seen, to mean that our experience indicates what a higher or inclusive, i.e. a more organised, experience would find presented thus or thus to itself. It is this meaning, this intent, this aim, this will to find in the moment the indication of what a higher experience directly grasps,-it is this that embodies for us the fact of which our hypothetical proposition aforesaid is the expression. But you may here say: "This aim, this will, is all. As a fact, you and I aim at the absolute experience; that is what we mean by wanting to know absolute truth; but the absolute experience," so you may insist, "is just a mere ideal. There need be no such experience as a concrete actuality. The aim, the intent, is the known fact. The rest is silence,--perhaps error. Perhaps there is no absolute truth, no ideally united and unfragmentary experience."

But hereupon one turns upon you with the inevitable dialectic of our problem itself. Grant hypothetically, if you choose, for a moment, that there is no universal experience as a concrete fact, but only the hope of it, the definition of it, the will to win it, the groaning and travail of the whole of finite experience in the search for it, in the error of believing that it is. Well, what will that mean? This ultimate limitation, this finally imprisoned finitude, this absolute fragmentariness and error, of the actual experience that aims at the absolute experience when there is no absolute experience at which to aim,-this absolute finiteness and erroneousness of the real experience, I say, will itself be a fact, a truth, a reality, and, as such, just the absolute truth. But this supposed ultimate truth will exist for whose experience? For the finite experience? No, for although our finite experience knows itself to be limited, still, just in so far as it is finite, it cannot know that there is no unity beyond its fragmentariness. For if any experience actually knew (that is, actually experienced) itself to be the whole of experience, it would have to experience how and why it were so. And if it knew this, it would be ipso facto an absolute, i.e. a completely self-possessed, experience, for which there was no truth that was not, as such, a datum,-no ideal of a beyond that was not, as such, judged by the facts to be meaningless,-no thought to which a presentation did not correspond, no presentation whose reality was not luminous to its comprehending thought. Only such an absolute experience 
could say with assurance: "Beyond my world there is no further experience actual." But if, by hypothesis, there is to be no such an experience, but only a limited collection of finite experiences, the question returns: The reality of this final limitation, the existence of no experience beyond the broken mass of finite fragments, -this is to be a truth,--but for whose experience is it to be a truth? Plainly, in the supposed case, it will be a truth nowhere presenteda truth for nobody. But, as we saw before, to assert any absolute reality as real is simply to assert an experience-and, in fact, just in so far as the reality is absolute, an absolute experience-for which this reality exists. To assert a truth as more than possible is to assert the concrete reality of an experience that knows this truth. Hence,--and here, indeed, is the conclusion of the whole matter,-the very effort hypothetically to assert that the whole world of experience is a world of fragmentary and finite experience is an effort involving a contradiction. Experience must constitute, in its entirety, one self-determined and consequently absolute and organised whole.

Otherwise put: All concrete or genuine, and not barely possible truth is, as such, a truth somewhere experienced. This is the inevitable result of the view with which we started when we said that without experience there is no knowledge. For truth is, so far as it is known. Now, this proposition applies as well to the totality of the world of finite experience as it does to the parts of that world. There must, then, be an experience to which is present the constitution (i.e. the actual limitation and narrowness) of all finite experience, just as surely as there is such a constitution. That there is nothing at all beyond this limited constitution must, as a fact, be present to this final experience. But this fact that the world of finite experience has no experience beyond it could not be present, as a fact, to any but an absolute experience which knew all that is or that genuinely can be known; and the proposition that a totality of finite experience could exist without there being any absolute experience, thus proves to be simply self-contradictory.

\section{Summary of the Whole Argument for the Reality of the Omniscient}

Let us sum up, in a few words, our whole argument. There is, for us as we are, experience. Our thought undertakes the interpretation of this experience. Every intelligent interpretation of an experience 
involves, however, the appeal from this experienced fragment to some more organised whole of experience, in whose unity this fragment is conceived as finding its organic place. To talk of any reality which this fragmentary experience indicates, is to conceive this reality as the content of the more organised experience. To assert that there is any absolutely real fact indicated by our experience, is to regard this reality as presented to an absolutely organised experience, in which every fragment finds its place.

So far, indeed, in speaking of reality and an absolute experience, one talks of mere conceptual objects,-one deals, as the mathematical sciences do, with what appear to be only shadowy Platonic ideas. The question arises: Do these Platonic ideas of the absolute reality, and of the absolutely organised experience, stand for anything but merely ideal or possible entities? The right answer to this question comes, if one first assumes, for argument's sake, that such answer is negative, and that there is no organised, but only a fragmentary experience. For then one has to define the alternative that is to be opposed to the supposedly erroneous conception of an absolute experience. That alternative, as pointed out, is a world of fragmentary experiences, whose limited nature is not determined by any all-pervading idea. Such a world of finite experiences is to be merely what it happens to be,-is to contain only what chances here or there to be felt. But hereupon arises the question: What reality has this fact of the limitation and fragmentariness of the actual world of experiences? If every reality has to exist just in so far as there is experience of its existence, then the determination of the world of experience to be this world and no other, the fact that reality contains no other facts than these, is, as the supposed final reality, itself the object of one experience, for which the fragmentariness of the finite world appears as a presented and absolute fact, beyond which no reality is to be viewed as even genuinely possible. For this final experience, the conception of any possible experience beyond is known as an ungrounded conception, as an actual impossibility. But so, this final experience is by hypothesis forthwith defined as One, as all-inclusive, as determined by nothing beyond itself, as assured of the complete fulfillment of its own ideas concerning what is,-in brief, it becomes an absolute experience. The very effort to deny an absolute experience involves, then, the actual assertion of such an absolute experience.

Our result, then, is: There is an Absolute Experience, for which the conception of an absolute reality, i.e. the conception of a system 
of ideal truth, is fulfilled by the very contents that get presented to this Experience. This Absolute Experience is related to our experience as an organic whole to its own fragments. It is an experience which finds fulfilled all that the completest thought can rationally conceive as genuinely possible. Herein lies its definition as an Absolute. For the Absolute Experience, as for ours, there are data, contents, facts. But these data, these contents, express, for the Absolute Experience, its own meaning, its thought, its ideas. Contents beyond these that it possesses, the Absolute Experience knows to be, in genuine truth, impossible. Hence its contents are indeed particular,-a selection from the world of bare or merely conceptual possibilities,-but they form a self-determined whole, than which nothing completer, more organic, more fulfilled, more transparent, or more complete in meaning, is concretely or genuinely possible. On the other hand, these contents are not foreign to those of our finite experience, but are inclusive of them in the unity of one life.

\section{This Conception of God in its Relations to Historic Philosophy and Faith}

The conception now reached I regard as the philosophical conception of God. Some of you may observe that in the foregoing account I have often, in defining the Absolute, made use of the terms lately employed by Mr. Bradley, ${ }^{1}$ rather than of the terms used in either of my two published discussions of the topic, i. e. either in the book that you have been studying or in my Spirit of Modern Philosophy. Such variation of the terms employed involves indeed an enrichment, but certainly no essential change in the conception. The argument here used is essentially the same as the one before employed. You can certainly, and, as I still hold, quite properly, define the Absolute as Thought. But then you mean, as in my book I explicitly showed, a thought that is no longer, like ours in the exact sciences, concerned with the shadowy Platonic ideas, viewed as conceptional possibilities, but a thought that sees its own fulfilment in the world of its self-possessed life,-in other words, a thought whose Ideas are not mere shadows, but have an aspect in which they are felt as well as meant, appreciated as well as described,-yes, I should unhesitatingly say, loved as well as con-

1 F. H. Bradley: Appearance and Reality. London: Swan Sonnenschein \& Co., 1893 . 
ceived, willed as well as viewed. Such an Absolute Thought you can also call, in its wholeness, a Self; for it beholds the fulfilment of its own thinking, and views the determined character of its living experience as identical with what its universal conceptions mean. All these names: "Absolute Self," "Absolute Thought," "Absolute Experience," are not, indeed, mere indifferent names for the inexpressible truth; but, when carefully defined through the very process of their construction, they are equally valuable expressions of different aspects of the same truth. God is known as Thought fulfilled; as Experience absolutely organised, so as to have one ideal unity of meaning; as Truth transparent to itself; as Life in absolute accordance with idea; as Selfhood eternally obtained. And all this the Absolute is in concrete unity, not in mere variety.

Yet our purpose here is not religious but speculative. It is not mine to-night to declare the glory of the Divine Being, but simply to scrutinise the definition of the Absolute. The heart of my whole argument, here as in my book, has been the insistence that all these seemingly so transcendent and imprudent speculations about the Absolute are, as a fact, the mere effort to express, as coherently as may be, the commonplace implications of our very human ignorance itself. People think it very modest to say: We cannot know what the Absolute Reality is. They forget that to make this assertion implies-unless one is using idle words without sense-that one knows what the term "Absolute Reality" means. People think it easy to say: We can be sure of only what our own finite experience presents. They forget that if a world of finite experience exists at all, this world must have a consistently definable constitution, in order that it may exist. Its constitution, however, turns out to be such that an Absolute Experience-namely, an experience acquainted with limitation only in so far as this limitation is determined by the organised and transparent constitution of this experience-is needed as that for which the fragmentary constitution of the finite world of experience exists. The very watchword, then, of our whole doctrine is this: All knowledge is of something experienced. For this means that nothing actually exists save what is somewhere experienced. If this be true, then the total limitation, the determination, the fragmentariness, the ignorance, the error,yes (as forms or cases of ignorance and error), the evil, the pain, the horror, the longing, the travail, the faith, the devotion, the endless flight from its own worthlessness,-that constitutes the 
very essence of the world of finite experience, is, as a positive reality, somewhere so experienced in its wholeness that this entire constitution of the finite appears as a world beyond which, in its whole constitution, nothing exists or can exist. But, for such an experience, this constitution of the finite is a fact determined from an absolute point of view, and every finite incompleteness and struggle appears as a part of a whole in whose wholeness the fragments find their true place, the ideas their realisation, the seeking its fulfilment, and our whole life its truth, and so its eternal rest,that peace which transcends the storms of its agony and its restlessness. For this agony and restlessness are the very embodiment of an incomplete experience, of a finite ignorance.

Do you ask, then: Where in our human world does God get revealed?-what manifests his glory? I answer: Our ignorance, our fallibility, our imperfection, and so, as forms of this ignorance and imperfection, our experience of longing, of strife, of pain, of error, -yes, of whatever, as finite, declares that its truth lies in its limitation, and so lies beyond itself. These things, wherein we taste the bitterness of our finitude, are what they are because they mean more than they contain, imply what is beyond them, refuse to exist by themselves, and, at the very moment of confessing their own fragmentary falsity, assure us of the reality of that fulfilment which is the life of God.

The conception of God thus reached offers itself to you, not as destroying, but as fulfilling, the large collection of slowly evolving notions that have appeared in the course of history in connection with the name of God.

The foregoing definition of God as an Absolute Experience transparently fulfilling a system of organised ideas, is, as you all doubtless are aware, in essence identical with the conception first reached, but very faintly and briefly developed, by Aristotle. Another definition of God, as the Absolute (or Perfect) Reality, long struggled in the history of speculation with this idea of God as Fulfilled Thought, or as Self-possessed Experience. The interrelation of these two central definitions has long occupied philosophical thinking. Their rational identification is the work of recent speculation. The all-powerful and righteous World-Creator of the Old and New Testaments was first conceived, not speculatively, but ethically; and it is to the rich experience of Christian mysticism that the historical honour belongs, of having bridged 
the gulf that seemed to separate, and that to many minds still separates, the God of practical faith from the God of philosophical definition. Mysticism is not philosophy; but, as a stage of human experience, it is the link that binds the contemplative to the practical in the history of religion, since the saints have taken refuge in it, and the philosophers have endeavoured to emerge from its mysteries to the light of clearer insight. To St. Thomas Aquinas belongs the credit of the first explicit and fully developed synthesis of the Aristotelian and the Christian conception of God. The Thomistic proofs of God's existence-repeated, diluted, and thus often rendered very trivial, by popular apologetic writers-have now, at best, lost much of their speculative interest. But the conception of the Divine that St. Thomas reached remains in certain important respects central, and in essence identical, I think, with the definition that I have here tried to repeat; and that, too, despite the paradoxes and the errors involved in the traditional concept of the creation of the world.

For the rest, let me in closing be perfectly frank with you. I myself am one of those students whom a more modern and radical scepticism has, indeed, put in general very much out of sympathy with many of what seem to me the unessential accidents of religious tradition as represented in the historical faith; and for such students this scepticism has transformed, in many ways, our methods of defining our relation to truth. But this scepticism has not thrown even the most radical of us, if we are enlightened, out of a close, a rational, a spiritually intelligent relation to those deep ideas that, despite all these accidents, have moulded the heart of the history of religion. In brief, then, the foregoing conception of God undertakes to be distinctly theistic, and not pantheistic. It is not the conception of any Unconscious Reality, into which finite beings are absorbed; nor of a Universal Substance, in whose law our ethical independence is lost; nor of an Ineffable Mystery, which we can only silently adore. On the contrary, every ethical predicate that the highest religious faith of the past has attributed to God is capable of exact interpretation in terms of our present view. For my own part, then, while I wish to be no slave of any tradition, I am certainly disposed to insist that what the faith of our fathers has genuinely meant by God, is, despite all the blindness and all the unessential accidents of religious tradition, identical with the inevitable outcome of a reflective philosophy. 